Samuel Luiz Velázquez Castellanos Universidade Federal do MaranhaoUFMA

E- mail: samuel@ufma.br

(D) https://orcid.org/0000-0003-0849-348X

\section{A instrução da criança desvalida no Maranhão oitocentista}

\section{Samuel Luiz Velázquez Castellanos}

\section{Resumo}

O crescente aumento da pobreza na Província do Maranhão nos oitocentos, após a Revolta da Balaiada, contribui com a criação da Casa dos Educandos Artífices, em 1841, que recolhe crianças desvalidas do sexo masculino. Os admitidos aprendiam as primeiras letras, a doutrina cristã e recebiam uma instrução mecânica, que era adquirida no Arsenal de Guerra, nas obras públicas do governo e em oficinas particulares. O ensino, dividido em lições teóricas e literárias, é organizado como as demais aulas de instrução primária: educandos que aprendiam a ler, escrever e contar, recebiam noções de gramática nacional e aulas de música vocal e instrumental. A modalidade profissional consistia na aprendizagem de uma arte mecânica: pedreiro, alfaiate, marceneiro, serralheiro e tanoeiro. Objetiva-se resgatar o ciclo de vida dessa Instituição, que culmina com a Proclamação da República, recorrendo-se ao cruzamento de diversas fontes: manuscritas; ofícios dos diretores aos presidentes de Província; relatórios dos próprios presidentes de Província; regulamentos; leis e os jornais que circularam em São Luís no período de 1841 a 1889 , à luz dos aportes teóricos de Norbert Elias. As categorias de análises adotadas foram: processos de criação e instalação da Instituição; caracterização e utilização do espaço físico, relações de poder (entre diretor, escrivão e professores); fluxo das disciplinas e organização do tempo escolar; professores, legislação, normas e administração. Contribui-se, com esta pesquisa, para compreendermos a natureza da instrução profissional e as características das instituições escolares destinadas ao acolhimento de crianças desvalidas no Maranhão do século XIX.

Palavras-chave: Instrução infantil. Casa dos Educandos Artífices. Instituição escolar.
Recebido em: 13/03/2019 Aprovado em: 20/09/2019 
Abstract

\section{Keywords:}

Infant education.

House

Educandos

Artificers. School institution.

\section{Resumen}

Palabras clave: Instrucción infantil. Casa de los Educandos Artífices. Institución escolar
The art of civilizing oneself through reading books: a study of the graduated series of the primary school in the city of São Paulo (1890-1904)

The growing increase in poverty in the Province of Maranhao in the 1980s, after the Balaiada Revolt, contributed to the creation of the Casa dos Educandos Artifices in 1841, which collects underprivileged children. Those admitted were taught the first letters, the Christian doctrine, and received a mechanical instruction that was acquired in the Arsenal de Guerra, the public works of the government and in private workshops. Teaching divided into theoretical and literary lessons is organized like the other classes of primary education; learners who learned to read, write and count; received notions of national grammar and vocal and instrumental music classes. The professional modality consisted of learning a mechanical art: mason, tailor, carpenter, locksmith and cooper. The objective is to rescue the life cycle of this Institution that culminates with the Proclamation of the Republic, resorting to the crossing of several sources: handwritten; offices of the directors to the presidents of the Province; reports of the provincial presidents themselves; regulations; laws and the newspapers that circulated in São Luís in the period of 1841 to 1889, in the light of the theoretical contributions of Norbert Elias. The categories of analysis adopted were: institution creation and installation processes; characterization and use of physical space, power relations (between director, clerk and teachers); flow of disciplines and organization of school time; teachers, legislation, standards and administration. We contributed to this research to understand the nature of the professional education and the characteristics of the school institutions destined to the reception of underprivileged children in Maranhão of century XIX

\section{La instrucción de niños desvalidos en el Maranhão ochocentista}

El creciente aumento de la pobreza en la Provincia de Maranhão en los ochocientos, después del Levante de la Baliadada, contribuye con la creación de la Casa de los Educandos Artífices en 1841 que recoge niños desvalidos del sexo masculino. Los admitidos aprendían las primeras letras, la doctrina cristiana y recibían una instrucción mecánica que se adquiría en el Arsenal de Guerra, en las obras públicas del gobierno y en oficinas particulares. La enseñanza dividida en lecciones teóricas y literarias es organizada como las demás clases de la instrucción primaria; educandos que aprendían a leer, escribir y contar; recibían nociones de gramática nacional y clases de música vocal e instrumental. La modalidad profesional consistía en el aprendizaje de un arte mecánico: albañil, carpintero, alfayate, cerrajero y "tanoeiro". Objetivase rescatar el ciclo de vida de esa institución que culmina con la Proclamación de la República, recorriéndose al cruzamiento de diversas fuentes: manuscritas; oficios de directores a los presidentes de Provincia; relatórios dos propios presidentes de Provincia; reglamentos; leyes y los periódicos que circularon en São Luís en el periodo de 1841 a 1889, a la luz de los aportes teóricos de Norbert Elias. Las categorías de análisis adoptadas fueron: procesos de creación e instalación de la institución; caracterización y utilización del espacio físico, relaciones de poder (entre director, secretario y profesores); flujo de las asignaras y organización del tiempo escolar; profesores, legislación, normas y administración. Contribuyese con esta investigación para comprenderse la naturaleza de la instrucción profesional y las características de las instituciones escolares destinadas al recogimiento de niños desvalidos en el Maranhão del siglo XIX. 


\section{As representações das Casas dos Educandos Artífices}

O período imperial pode ser caracterizado como uma época de transformações sociais, políticas, econômicas e educacionais significativas, influenciadas pelo movimento revolucionário francês de 1789 e pela Revolução Industrial. Tais eventos históricos contribuíram para a formação do pensamento liberal, que chegou ao Brasil nos vapores que transportavam imigrantes estrangeiros e também brasileiros que, indo estudar na Europa, traziam em suas bagagens as ideias positivistas de Comte. Em termos políticos, liberais e conservadores disputavam os cargos como forma de legitimidade, manutenção e estabelecimento das oligarquias enriquecidas com o crescimento da produção agrícola, a exemplo da cana-de-açúcar, do algodão e do café; ou seja, se a manutenção do escasso ensino nas colônias foi característica própria do predomínio lusitano, no Império, a pensada homogeneidade ideológica e de treinamento mediada pela instrução reduziria os conflitos intraelites e forneceria a concepção de determinado modelo de dominação política. Homogeneidade que se daria pelo processo de socialização das elites, direcionado à instrução, à ocupação e às carreiras políticas, segundo Carvalho (2006), e pelos poderes atribuídos às Assembleias Provinciais para nomear e demitir funcionários públicos, dando aos políticos locais ampla margem para trocas de favores, que foram retribuídos com votos ou perseguição dos inimigos (FAUSTO, 2003). Configuração de indivíduos formada por esta rede de interdependências que os ligam; uma vez que, se "[...] as pessoas são mais ou menos dependentes entre si, inicialmente por ação da natureza e mais tarde através da aprendizagem social, da educação, socialização e necessidades recíprocas socialmente geradas, elas existem [...] apenas como pluralidades [...] como configurações" (ELIAS, 1994, p. 249).

Essas novas ideias trouxeram como consequência a necessidade de criar instituições de poder e de controle social como a Guarda Nacional, formada em 1831, com a finalidade de armar e proteger os governos locais (principalmente o governo central) das 'classes perigosas', qual fossem, as classes populares (MALERBA, 1999, p. 48). Estes grupos, formados por bacharéis, pequenos proprietários de terras, médicos, comerciantes e outros, defendiam as ideias abolicionistas e republicanas (CARVALHO, 2006). Exemplos de movimentos populares foram a Cabanagem, que eclodiu no Pará, e a Balaiada, no Maranhão, com desdobramentos no Piauí, as quais emergiram a partir das disputas de grupos locais pelo poder e acabaram resultando em revoltas populares, arregimentando índios, mestiços, trabalhadores escravos, pequenos comerciantes e produtores de gado e algodão. ${ }^{1}$

Com relação à instrução, expandiram-se os liceus, estabelecimentos preparatórios para o Ensino Superior nos centros economicamente importantes, e as escolas normais, já que o 
Ato Adicional de 1834 conferiu poderes às Províncias para legislarem sobre o ensino secundário e elementar; porém, embora se tentasse cumprir com os dispositivos legais, ${ }^{2}$ não havia professores em número suficiente para dar conta dessa pseudodemocratização do ensino, realidade que contribui para expansão do método de ensino mútuo, ${ }^{3}$ introduzido no Brasil através da Carta de Lei de 15 de outubro de 1827.

O método lancasteriano foi adotado pelas Casas de Educandos Artífices do Pará, do Maranhão, do Amazonas, entre outras, como forma de "[...] diminuir as despesas da instrução, abreviar o trabalho do mestre e acelerar os progressos dos alunos" (MANACORDA, 1989, p. 257). No entanto, sua adoção, segundo Bastos (1999), deveu-se ao caráter disciplinador, hierarquizante, compensatório e punitivo do método: práticas instituídas para inculcar novos hábitos por meio do controle dos comportamentos, dos tempos e da racionalização do ensino. Os alunos que se destacavam pela capacidade de liderança e boa conduta eram premiados com livros, jogos ou dinheiro. Aqueles que não atendiam aos requisitos exigidos de um aprendiz no âmbito cognitivo, social e moral eram punidos e julgados em júri, com a subsequente aplicação de penas, entre as quais “[...] ficar em quarentena num banco particular; em isolamento num gabinete especial durante a aula; em solitária; permanecer na classe após o final dos exercícios [ou] em frente a um cartaz onde estão listadas as faltas cometidas, enfim, a expulsão da escola” (BASTOS, 1999, p. 101).

É evidente que a 'expansão' e a 'gratuidade' do ensino elementar precisaram ser controladas pelo olhar vigilante do governo central sobre as Províncias e destas sobre as suas freguesias. Isto levou à criação das Inspetorias de Ensino, com a finalidade de fiscalizar os estabelecimentos de ensino particulares e públicos, a fim de "[...] uniformizar a organização das aulas, as práticas docentes e os métodos e programas de ensino, com vistas a difundir pela cultura letrada o modelo unificado de civilização" (HILSDORF, 2005, p. 48). Civilidade que, na visão de Boto (2002), como programa pedagógico, foi fortalecida a partir do século XVI, em consonância com um longo e progressivo processo de "[...] privatização que caracteriza as sociedades ocidentais [:] inclui expectativas e práticas novas, produz espaços, objetos, escritos até então desconhecidos, cria uma inédita consciência de si mesmo e dos outros" (CHARTIER, 1991, p. 165). Práticas de civilidade (via instrução e profissionalização) que, nas Casas dos Educandos Artífices, originariam modificações no corpo e na mente dos indivíduos, ao introduzir hábitos e regimes disciplinares inseridos em processos simbólicos, que, na linguagem de Elias (1994), podemos denominar de processo civilizador. Processo este traduzido na corporificação de uma lenta e sutil aprendizagem, que se expressa em forma de capital cultural por meio da escolarização. O uso da mente, do corpo e de seus atributos, as habilidades, os valores e as atitudes reproduzem as relações de classe preconizadas num 
determinado espaço-tempo, no qual cada um aprende aspectos cognitivos, corporais, morais e societais apropriados às diferentes situações de vida e à sua condição social, fazendo com que o corpo e as formas de agir, de pensar e de se posicionar ganhem valor simbólico. São práticas de modelação dos sujeitos da infância e da adolescência que, segundo Warde (2007), constituem-se como configurações mentais ou psíquicas, nas quais cognição, sentimento, comportamento e valor não são passíveis de abstração (ELIAS, 1993, 2001a, 2001b).

Aos excluídos dos espaços públicos e particulares de formação elementar com vistas ao ensino secundário e superior, considerados como os desvalidos da sorte, entre os quais se enquadravam criminosos, indígenas, doentes e órfãos, restava-lhes uma instrução baseada em prescrições de normas psicofísicas geradas por dispositivos de coerção e por mecanismos de autocontrole (WARDE, 2007) que os corrigissem e os adaptassem ao conjunto de regras e preceitos instituídos por uma rede de poderes engendrada por policiais, médicos, padres, juízes, professores e outros responsáveis pela manutenção de uma "liberdade vigiada", como explicita Foucault (1987, p. 20). Para tanto, foram criadas instituições de controle "[...] das paixões, dos instintos, das enfermidades, das perversões, dos impulsos e desejos" (FOUCAULT, 1987, p. 19), como os Lazaretos, as Santas Casas da Misericórdia e as Casas dos Educandos Artífices, entre outras.

Os territórios de confinamento desses desvalidos da sorte, como formas de os governos provinciais manterem os exercícios de poder e o disciplinamento, ocupam as periferias das cidades, o que demarca uma característica de todas as Casas de Educandos Artífices, que tinham o fim comum de recolher crianças órfãs de pai ou mãe (ou de ambos) e os abandonados nas rodas dos expostos, os quais, sob uma ordem rigorosamente militar, deveriam aprender as primeiras letras e um ofício mecânico. Assim, no futuro, poderiam tornar-se homens de bem, capazes de se integrar à sociedade e contribuir para o desenvolvimento das artes industriais nas Províncias.

Além desses pré-requisitos de ingresso, deveriam ser fisicamente capazes de exercer as manobras de trabalho nas oficinas e nos exercícios militares, legitimados pelos discursos, pela avaliação e pela intervenção médicas, já que julgar as características básicas previstas nos modos de ser, de estar no mundo e de agir da criança-aluno "[...] é parcela integrante do longo processo de formação desse modo especificamente escolar de ser criança” (BOTO, 2002, p. 30). Aliás, essa intervenção era requisitada por todos os diretores dessas instituições, que viam na prática médica “o desaparecimento dos grandes surtos epidêmicos" que acometiam os educandos, como cóleras, febres intermitentes e beribéri, por exemplo. Daí as recomendações de criação de sistemas de evacuação, arejamento de espaços como dormitórios e cozinhas e o cuidado para com a alimentação dos doentes, o que fazia 
constantes as reivindicações dos diretores em torno da criação de enfermarias no interior das casas, como consta em todos os regulamentos e relatórios da instituição maranhense analisada. Além do mais, a existência de enfermarias evitava o contato dos educandos com outros 'anormais' (criminosos e leprosos, por exemplo) tratados nos hospitais gerais ou nas Santas Casas, uma vez que poderiam contaminar a moral dos meninos. Assim, estabelecia-se uma relação entre instrução e medicina como forma de saneamento e educação da sociedade, tal como evidenciada por Faria Filho (2004), Gondra (2004a, 2004b) e Kulhmann Júnior (2002), entre outros autores que tratam da história da infância.

Sendo assim, essas instituições originaram-se da necessidade de manutenção da ordem social e política; nos casos do Maranhão, do Piauí e do Pará, após as rebeliões populares citadas. Nas demais Províncias, configuravam-se como uma forma de criar um corpo de reserva para o exército - o que levou inicialmente a uma hesitação por parte de pais e tutores em entregarem seus filhos e protegidos aos cuidados dos governos -, constituindo-se ainda em uma maneira de formar mão de obra barata para as obras públicas do governo, a exemplo da confecção de materiais como fardamentos, sapatos e armas para os corpos policiais ou de móveis para instituições escolares e hospitalares.

As Casas de Educandos Artífices implicaram a criação de oficinas, entre as quais, no conjunto de todas as instituições, predominavam as de alfaiates, sapateiros, marceneiros, ferreiros, carpinteiros e funileiros, havendo, porém, algumas exceções: no Amazonas, eram mais frequentes as de confecção de chapéus de bombassaro; no Piauí, as de tipógrafos; e em São Paulo, as oficinas de encadernadores. Nessa dinâmica, a oferta do ensino profissionalizante, complementado pelas 'oficinas de homens', que se modificavam segundo o progresso das artes mecânicas (BOTO, 2002), seguiu o fluxo das mudanças econômicas das Províncias, com o fechamento ou (re)abertura de uma ou outra modalidade de ofício. Destarte, foi nos momentos em que as Províncias alcançaram maior desenvolvimento econômico, oriundo do capital acumulado pela produção agropecuária (de algodão, no Maranhão; de café, em São Paulo; pecuária, no Piauí; exportação de couro e gado, e a exploração da borracha, no Amazonas e no Pará) que ocorreu o maior 'progresso' dos estabelecimentos de artífices. Progresso que pode ser avaliado inclusive pelo ingresso de maior número de educandos, pela melhoria das condições da arquitetura dos edifícios e pela criação das oficinas, na contramão do fechamento de oficinas, do acréscimo de demissões e do encerramento total das atividades nas Casas do Ceará, do Rio Grande do Norte e de Alagoas. Já nas Províncias de Sergipe e Goiás, as condições econômicas não permitiram sequer a instalação destas instituições. 
A centralidade geográfica das Casas de Educandos Artífices nas regiões Norte e Nordeste, mapeadas por Cunha (1979), Freitas (1954), Fonseca (1986), Rizzini (2004) e Franco (1988), pode ter sido ocasionada por vários motivos, entre os quais: o crescimento demográfico desordenado, que intensificou o nível de pobreza, como ocorreu no Maranhão, quando da Balaiada; os surtos de industrialização, que ocasionaram a reabertura das Casas do Pará e, principalmente, do Amazonas, com a exploração da borracha, as quais passaram a ser denominadas de Institutos de Educandos Artífices; o número crescente de menores abandonados em estado de mendicância e vadiagem, ocasionado pela migração de excamponeses arruinados em São Paulo (FRANCO, 1988), e a presença de "pobres mulheres, brancas, escravas e forras" de todas as idades, que pariam e abandonavam seus filhos ou os entregavam a terceiros (DIAS, 1995, p. 193); o aumento da pobreza e a necessidade de formar mão de obra para as atividades manufatureiras da Província do Piauí, após a transferência da capital de Oeiras para Teresina; e a pobreza resultante das secas históricas na região do Ceará e em Alagoas, ocorrendo o mesmo nas Províncias do Rio Grande do Norte e da Paraíba.

Isso não significa que as demais Províncias não criassem estabelecimentos asilares (masculinos e femininos) de instrução elementar e profissional. Franco (1988) mapeou, no período de 1818 a 1925, cerca de 75 instituições com finalidades similares, denominadas de Casas de Educandos, Asilos, Institutos, Colégios, Colônias, Orfanatos, Externatos, Seminários, Escolas e Liceus de Artes e Ofícios. A diferença nuclear entre estes outros estabelecimentos e as Casas, Institutos ou Colégios de Educandos Artífices consistia no seguinte: além de uma formação primária e profissional - que garantisse a inserção no mundo 'civilizado' por meio da gradual transferência do controle institucional para o autocontrole/policiamento dos próprios indivíduos sobre os comportamentos/paixões particulares e o exercício de uma profissão específica que visasse ao desenvolvimento individual -, estas últimas instituições também adotavam os mesmos métodos pedagógicos utilizados pelos arsenais de guerra (mesmo os dirigidos por não militares), como acontecia no Ceará e na Paraíba, que foram administrados por religiosos e funcionaram em espaços próprios, mantidos pelos cofres provinciais. Essa dinâmica é diferente da adotada pelas Companhias de Aprendizes Menores, pois, embora tivessem a mesma finalidade no que se refere ao amoldamento e à disciplinarização de comportamentos infantis, os militares geriam o interior destas organizações, as quais foram sustentadas com recursos do governo central e objetivavam formar um contingente para o exército, como se depreende do relatório apresentado por Gonçalves Dias ao governo central em 1852. Formação de profissões e exercício de ocupações que, “[...] se despojadas de suas roupagens próprias, são funções sociais especializadas que as pessoas desempenham em resposta a necessidades 
especializadas de outras; são, ao menos em sua forma mais desenvolvida, conjuntos especializados de relações humanas” (ELIAS, 2001b, p. 90), que travam constantemente “[...] tensões de grupo e conflitos institucionais causados pelo padrão institucional de suas relações e suas funções [...]" (ELIAS, 2001b, p. 108). Relações e funções que devem ser analisadas em conjunto quando nos referimos à formação das profissões e ao exercício das ocupações, embora para o escopo deste trabalho se faça um tanto limitado. ${ }^{4}$

O relatório de 1852, ao descrever as Companhias de Aprendizes Menores ligadas aos Arsenais de Guerra, afirmara que as do Pará, Pernambuco e Bahia tinham melhores condições. Nesta última, havia cem alunos que aprendiam desenho, além de quatorze ofícios para os 97 alunos que cursavam as primeiras letras e onze ofícios mecânicos em Pernambuco e os 48 meninos aprendizes no Pará, com suas cinco oficinas. O local onde funcionavam essas Companhias era "mal arejado, pouco susceptível de asseio, pouco próprio para a escola":

\begin{abstract}
Além dos estabelecimentos gerais que acabamos de falar, outros há nas províncias que têm patrimônio, de que subsistem. Nestes são admitidos meninos pobres, que recebem a conveniente educação e instrução primaria com o aprendizado de um oficio mecânico, de modo que, tendo compensado com seu trabalho os gastos que fizeram, tenham um modo de vida, pelo qual se tornem úteis a si e à sociedade que os educa. Tais são as casas de educandos do Maranhão e Pará. Mas a do Pará, constando no ano findo de 12 alunos somente, estava em tal estado de decadência que a sua falta não seria sensível à província, principalmente tendo ela uma Companhia de Aprendizes Menores. De fato, o número de educandos paraenses decrescia espantosamente desde 1850. [...] Apontei algumas das causas da decadência daquele estabelecimento [...]. O interior da casa em que se acham está em ruínas; aos meninos faltam rêdes, camas ou tarimbas, e muitas vezes, roupa, uniforme e calçado [...]. A última, enfim, é que o atual diretor, desanimado ou por qualquer outro motivo, não sabe ou não julgue possível melhorar a atualidade, e por conseqüência inútil qualquer tentativa. A Casa dos educandos no MARANHÃO nem só é o mais completo estabelecimento no seu gênero, mas o que unicamente tem prosperado dos ensaios que em outras partes se fizeram: tem um bom diretor $e$ hábeis professores. (DIAS, 1852, p. 5, grifo nosso).
\end{abstract}

Como organizações de princípios militares, as Casas de Educandos Artífices tinham um esquema de disciplinamento dos gestos, dos trabalhos, dos conteúdos escolares e da linguagem dos meninos que funcionava de forma ininterrupta, com a finalidade de "esquadrilhar o tempo, o espaço e o movimento" (FOUCAULT, 1987, p. 118), estabelecendo relações de "docilidade-utilidade" para o trabalho mecânico, para as aulas teóricas e, principalmente, nas relações que os alunos estabeleciam com os seus superiores. Esses mecanismos de poder empregados pelos diretores, como responsáveis pela ordem e o controle, eram materializados nos atos de vigilância e de punição das contravenções como emblema da autoridade e foram respaldados pelos regulamentos, criados com a finalidade de controlar as atividades e o ritmo do aparelho disciplinador por meio de prescrições e normas. Noutras palavras, para Warde (2007), a escola e suas práticas pedagógicas destinadas à 
escolarização e ao exercício de uma profissão, exigidas, neste caso, pelas Casas dos Educandos e Artífices, funcionaram como práticas modeladoras de práticas e a existência destes estabelecimentos como espaços de ensino e formação de ocupações permite que se fale da história da infância como história de uma "prática ortopédica" (FOUCAULT, 1975). Instituições que zelavam para que a ocupação temporal das atividades dos meninos fosse distribuída de modo a anular "[...] tudo o que possa perturbar e distrair; [a fim] de constituir um tempo integralmente útil" (FOUCAULT, 1987, p. 118), mesmo para aqueles que tinham sete anos - menor idade de admissão. Regulação do tempo que começava nas primeiras horas da manhã e terminava pela noite, após o trabalho nas oficinas. As aulas e as minguadas refeições não diferiam muito das regulações adotadas nas "Casas de Jovens" detentos de Paris, como descreve Foucault (1987, p. 10).

Para tanto, um corpo de vigilância hierarquicamente organizado sob a forma de seções e divisões era encarregado da distribuição das tarefas, do controle do tempo e da manutenção da ordem, como os agentes, almoxarifes, mestres das oficinas e professores; ou seja, o treinamento dos escolares devia ser feito "[...] da mesma maneira, poucas palavras, nenhuma explicação, no máximo um silêncio total que só seria interrompido por sinais [...]. O 'sinal' deveria significar em sua brevidade maquinal ao mesmo tempo a técnica do comando e a moral da obediência” (FOUCAULT, 1987, p. 140). Em outras palavras, a cada 'badalada' das sinetas das casas, sob o comando dos diretores, os educandos executavam uma atividade: almoço, trabalho nas oficinas, orações, etc.

Esse 'microscópio do comportamento' dos educados artífices se estendia aos dormitórios, como forma de evitar o contato físico entre educandos, as práticas masturbatórias e/ou as fugas, e, no caso da instituição maranhense, o encontro com prostitutas. Esses mecanismos de vigilância e autoridade moral se configuravam ainda como formas de manter o distanciamento entre os meninos de maior e os de menor idade, estabelecendo-se como parâmetro os 14 anos de idade. Ou seja, embora a primeira infância, a puerilidade (considerada como segunda infância, que oscila entre 7 e 12 anos) ${ }^{5}$ e seu terceiro estágio (entre 12 e 13 anos), considerado por Rousseau como "[...] o único período da vida humana em que o progresso das forças superaria o das necessidades" (BOTO, 2002, p. 51), sejam etapas que contrapõem a infância à adolescência, os instrumentos disciplinadores e as estruturas de controle/modelamento, segundo as fontes em análise, parecem apontar a adolescência como divisor de águas das práticas de ensino, dos controles morais, da sedução ao autocontrole e policiamento individual das emoções da criança e do adolescente alunos, evitando-se assim a proliferação de doenças ou as deturpações juvenis, como relatam os diretores da Casa maranhense, no intuito de formar vias práticas de civilidade, jovens bom- 
probos e futuros homens de bem aptos a se inserirem no tecido societal. Sentido de civilidade que, de alguma maneira, parte do que se entende por processo civilizador, o qual está sustentado em mudanças nas formas de ser e de existir que se entrelaçam com as transformações sociais no devir histórico; mudanças na estrutura mental e na estrutura social que acarretam relações de interdependência entre o desenvolvimento moral e social. Civilização que, na visão de Elias (2001a, p. 70), “[...] estamos acostumados a considerar como uma posse que aparentemente nos chega pronta e acabada, sem que perguntemos como viemos a possuí-la, um processo ou parte de um processo em que nós mesmos estamos envolvidos".

Sob os olhares dos disciplinadores, as quebras das regras acarretavam punições que, dependendo da gravidade da contravenção, variavam desde a exposição pública em frente a todo o corpo enfileirado, a obrigação de servir as mesas dos demais alunos, o corte de uma das refeições e a prisão por dias no xadrez da casa, até, nos casos mais graves, a expulsão ou o envio do contraventor aos Arsenais da Marinha e de Guerra. A punição era vista pelos diretores como necessária para o ajustamento social dos educandos; após concluírem seu tempo de aprendizado e, com o aval deles, os mestres e professores podiam decidir por outras penalidades, como o uso da palmatória, as repetições de exercícios inúmeras vezes e outras formas que julgassem convenientes ao processo de aprendizagem.

A hierarquização das penalidades levava a uma classificação meritocrática dos educandos, divididos segundo critérios de capacidade moral, capacidade intelectual e capacidade industrial. Em outras palavras, eram anualmente premiados aqueles que se mostravam ajustados aos métodos de ensino teórico e profissional e, principalmente, os obedientes e defensores da ordem. Aqueles que não apresentavam aptidão para a escrita, a leitura e o trabalho mecânico eram denominados de bastardos, imbecis ou inaptos, estabelecendo-se diferença entre os que mereciam a benevolência dos diretores e os que estavam utilizando indevidamente os recursos dos cofres provinciais.

As capacidades intelectual e industrial eram medidas a partir dos exames públicos anuais, enquanto a capacidade moral era avaliada pelos agentes de vigilância: diretor, mestres e professores. Os exames e premiações serviam de objeto de exposição pública e de justificativa aos governos para propagar a importância de as instituições estarem devolvendo à sociedade homens ordeiros e trabalhadores, que contribuiriam com o desenvolvimento das artes industriais, tão necessárias à Província.

O exame está no centro dos processos que constituem o indivíduo como efeito e objeto de poder, como efeito de saber. É ele que, combinando vigilância hierárquica e sanção normalizadora, realiza as grandes funções disciplinares de repartição e 
classificação, de extração máxima das forças e do tempo, de acumulação genética contínua, de composição ótima das aptidões. [...] Com ele se ritualizam aquelas disciplinas que se pode caracterizar com uma palavra, dizendo que são uma modalidade de poder para o qual a diferença individual é pertinente. (FOUCAULT, 1987, p. 160).

A Casa dos Educandos Artífices do Maranhão (CEA) foi criada através da Lei Provincial $n^{\circ} 105$, de 23 de agosto de 1841, e inaugurada em novembro desse mesmo ano, sob a direção de José Antônio Falcão, para atender "[...] moços desvalidos, de preferência os enjeitados, e dar-lhes instrução, primeiras letras e um oficio" (VIVEIROS, 1953, p. 15). Quando da sua inauguração, contava com 28 meninos matriculados, uns oriundos da Casa dos Expostos, outros enviados pelos juízes de órfãos ou por indicação do presidente da Província. Para o seu funcionamento, o governo adquiriu mobiliários, tecidos para garantir o vestuário das crianças e instrumentos para as oficinas; entretanto, por falta de acomodações adequadas, no primeiro ano, os educandos aprenderam os ofícios mecânicos fora do estabelecimento. Segundo Marques (1970), como esse sistema de aprendizagem concorria para a indisciplina e a desmoralização dos educandos, foram montadas várias oficinas no interior da Casa, algumas das quais, no decorrer dos anos, foram extintas por motivos diversos, enquanto outras apresentaram significativa representatividade, a exemplo das de serralheiro, de alfaiate e de carpinteiro.

A estrutura física da Casa, quando de sua criação, constava com salas de carpintaria, de carpina, de pedreiro e de sapateiro, uma enfermaria (com um enfermeiro e dois ajudantes de enfermaria), cozinha, capela, dormitórios e sala de aulas para o ensino de primeiras letras. Nos anos posteriores, outras oficinas foram criadas, como as de alfaiate, de espingardeiro e de música. Esta última, a partir dos anos 1850, tornou-se uma das mais rentáveis fontes de captação de recursos para a Casa e também um meio de angariar reconhecimento e prestígio social, em razão das apresentações realizadas em eventos e locais públicos. Esse reconhecimento e a ampliação do número das oficinas representaram, por um lado, oportunidades de acesso a um maior número de crianças; mas, por outro, acarretaram um significativo aumento das despesas, que chegou a causar atritos entre a direção e o tesouro provincial, uma vez que a Casa dos Educandos atingiu o quantitativo de 300 alunos atendidos em 1873 (CABRAL, 1989).

Mesmo contando com um número significativo de alunos e com a ampliação do número de oficinas e das aulas de primeiras letras, com o acréscimo das aulas de música e de instrumentos de sopro e corda, a Casa dos Educandos Artífices, a partir de 1873, começou a apresentar sinais de declínio, que se tornaram evidentes após a implementação da Lei $n^{\circ}$ 1.096, de 18 de junho de 1874, quando se reduziu para cem o número de educandos. Nos anos 
subsequentes, embora o quadro tenha permanecido inalterado, mesmo assim diminuiu o número de oficinas, funcionando apenas quatro delas em 1884. Com o advento da República, a Casa dos Educandos encerraria de vez suas atividades; uma instituição que, "Não obstante [fosse uma] grande obra de filantropia, depois de 48 anos de vida fecunda e brilhante, foi suprimida a 13 de dezembro de 1889, pela junta de Governo Provisório do Estado, nos albores da República" (VIVEIROS, 1953, p. 16-17, grifo nosso).

\section{Aula de Primeiras Letras}

Desde a criação da Casa dos Educandos Artífices, foi determinado que, dentre as atividades de ensino, além dos ofícios mecânicos, os educandos deveriam receber "a instrucção de primeiras letras e princípios religiosos" (REGULAMENTO, 1841, Art. $3^{\circ}$ ). Se considerarmos a CEA como uma figuração ou formação social com dimensões variáveis, “[...] em que os indivíduos estão ligados uns aos outros por um modo específico de dependências recíprocas e cuja reprodução supõe um equilíbrio móvel de tensões [...]” (ELIAS, 2001a, p. 47), conseguiremos divisar os papéis, as funções e as relações entre essas funções geridas pelos presidentes de Província, por inspetores da instrução pública, diretores, professores e os próprios educandos. Nesse sentido, com respeito às aulas, estas deveriam ser ministradas por um "homem de boa fama e reputação" e habilitado para "ensinar a leitura, escripta, artithmetica, e princípios de escripturação" (REGULAMENTO, 1848, Art. 50). A regularidade desses estudos era diária, das 6 às 8 horas, com exceção das quintas-feiras. Por outro lado, os alunos deviam se fazer presentes "vestidos com toda a decência" e "[...] cumprir o regulamento da casa em geral, e com especialidade os regulamentos relativos às aulas nella existentes" (REGULAMENTO, 1855, Art. 42).

No dia 2 de janeiro de 1842, iniciaram-se as aulas de primeiras letras, sob a regência do professor Manuel Ferreira Freire, que, juntamente com José Antonio Falcão, elaborou o regulamento da aula, denominado de practica para o serviço da eschola. Esse professor contava com o auxílio de educandos, que exerciam as funções de imediatos e decuriões. As atividades do imediato era formar os alunos por decúrias, entregar a tabuada, a carta e o caderno de escrita aos decuriões e cuidar do asseio e do arranjo da escola. Por sua vez, ao receberem do imediato os materiais didáticos, os decuriões repassavam-nos aos decuriados e os acompanhavam em suas lições de leitura e caligrafia, todos os dias da semana (com exceção das quintas-feiras), e, aos sábados, repassavam com eles os "[...] princípios aritméticos, estudados, repetidos e executados" (REGULAMENTO, 1855, Art. 42). As quintas-feiras e os sábados, nos primórdios da instituição, eram dias dedicados especificamente à manutenção do prédio e à limpeza externa e interna das suas dependências, 
como forma de responsabilizar os educandos pela organização e higiene do estabelecimento. Mecanismos de controle dos comportamentos e das condutas de ordem geral que se refletiriam no autocontrole individual das ações de forma orgânica, visando a mudanças nas estruturas psíquicas singulares dos educandos com vistas à sua inserção no tecido societal.

Os exercícios eram feitos nas "louzas e depois transcritos em caderno", com cabeçalho indicando a data e os nomes da escola e do educando. Depois de usado na sala de aula, esse material era guardado no arquivo da escola, com a finalidade de não "estragar ou perder os cadernos" (REGULAMENTO, 1855, Art. 42). Aos alunos que não conseguiam ler, escrever e contar, ou que tivessem uma má caligrafia, o professor aplicava castigos por ordem do diretor. A punição mais frequente consistia em doze "bolos de palmatória de cada vez" (PRACTICA, 1845, Art. 21). Outros castigos podiam ser aplicados, de modo a garantir que "As regras de respeito e subordinação e as de ordem moral, serão religiosamente praticadas na escola." (PRACTICA, 1845, Art. 23). Práticas de ensino e controle dos comportamentos que moldam as mentes e os corpos das crianças e jovens, trazendo consigo novas configurações mentais e psíquicas, que fazem referência, segundo Elias (1990, p. 80), “[...] a um novo padrão de relações humanas e uma estrutura de sentimento; [ou seja] novos comportamentos adquiridos, [aos quais] corresponde outro padrão de relações e outra estrutura de sentimento", como também “[...] outro padrão cognitivo e outra estrutura cognitiva” (WARDE, 2007. p. 32).

Não havia, entretanto, cadernos, tabuadas, catecismos nem livros para todos os educandos. Segundo o professor Colin (1860, p. 9), "Os livros existentes estavam muito deteriorados e adequados somente para os alunos que estavam aprendendo a ler, mas não para os que tivessem mais adiantados, estes careciam de compêndios e livros em que [podiam] beber instrução mais variada.” Somente em 1862 a carência de livros foi minimizada, com a doação, por parte dos comerciantes locais, d'O Livro do povo, obra indicada para o ensino da leitura que foi destinada a todas as aulas de primeiras letras da Província, cabendo à CEA 75 exemplares, os quais foram cedidos aos alunos que se distinguiam pela assiduidade, pelo aproveitamento e pela moralidade. ${ }^{6}$ Iniciativa que, se para o professor Colin era uma forma de premiar os alunos dedicados aos estudos, por outro lado, parece apontar que 41 educandos não aprendiam a ler, escrever, contar ou rezar nem tinham comportamentos moralmente aceitáveis, uma vez que 116 meninos frequentavam essa aula na época. Nestes termos, o equilíbrio das tensões entre a distribuição dos livros como cultura material escolar sujeita à vontade de terceiros, e não ao cumprimento do governo provincial, como se institui em lei, e o nível de consumo relacionado às táticas de apropriação dos alunos segundo o aproveitamento de tais práticas, que dependem da natureza da obra enquanto concepção e fabrico direcionados a um público-alvo específico, coloca em suspeita metodologias de 
classificação/avaliação de saberes e aprendizagens pela instituição das próprias práticas, já que não se identifica na documentação nem o nível de maturidade cognitiva das crianças nem a idade daqueles que foram obsequiados, o que impossibilita estabelecer relações ou comparações entre idade, aproveitamento e nível de moralidade; mesmo que em 1889 já se anunciasse um grande número de crianças pequenas na instituição.

Em 1889, a aposentadoria do professor Colin se efetuou diante de uma grande crise no estabelecimento e, em particular, nas aulas de primeiras letras, sendo substituído por Innocencio de Lemos, que passou a ministrar essa aula a 134 alunos, dos quais dois terços eram muito pequenos e, portanto, "não podiam obter qualquer aproveitamento", o que pode indicar vestígios da relação pedagógica estabelecida (intencional ou não) entre o nível do ensino imposto e das práticas dos ofícios que se direcionavam aos educandos e a faixa etária/maturidade cognitiva correspondente. Nessa lógica, os problemas relativos a essa aula foram recorrentes em todas as outras criadas no decorrer do ciclo de vida da CEA: escultura e desenho, instrumentos de corda, geometria aplicada às artes, entre outras.

\section{Aula de escultura e desenho aplicada às artes}

Essa disciplina foi criada pela Lei $\mathrm{n}^{\mathrm{o}} 243$, de 16 de outubro de 1848 , sob a justificativa, por parte do presidente da Província, Antonio Joaquim Álvares do Amaral, de que:

Conviria que, além das officinas existentes, também se estabelecesse huma de esculptura para os moços, que mostrassem mais algum talento, bem como que d'aquellas obras, que fossem melhor manufacturadas, e que alguma invenção se fizesse no fim de cada anno huma exposição publica, e se distribuíssem alguns prêmios para excitar a evolução dentre estes jovens artífices. (FALLA, 1848).

A aula de escultura e desenho podia ser frequentada pelos alunos internos e externos à CEA. Para ministrá-la, eram contratados professores que provassem sua maioridade e moralidade através "[...] de folhas corridas nos lugares onde tenhão residido nos três annos proximos à data de seu requerimento, e atestados dos respectivos parochos" (INSTRUCÇÃO, 1855, Art. 6). Nesse caso, não podia “[...] ser nomeado professor público ou individuo, que tiver soffrido pena de galés, ou condemnação judicial por crime de furto, roubo, estellionato, bancarôta, rapto, incesto, adultério, ou outro qualquer, que offenda a moral publica ou a religião do estado" (INSTRUÇÃO, 1855, Art. 7). Além disso, o professor deveria ter a capacidade profissional comprovada por exame realizado em presença de três examinadores de reconhecida competência, nomeados pelo governo e pelo inspetor da instrução pública, recebendo a gratificação anual de quinhentos mil réis e submetendo-se a mesma fiscalização que os professores do Liceu, “[...] servindo porem de delegado da Instrução Pública no 
estabelecimento o seu respectivo diretor" (Lei n ${ }^{\circ}$ 243/1848, Art. 3). Mas, na falta de professor na Província do Maranhão, o presidente podia contratá-lo no estrangeiro, por um prazo mínimo de três anos, na medida em que a "[...] cadeira [era] temporária e o seu professor [seria] conservado somente em quanto convie[sse] ao serviço público" (Lei no 243/1848, Art. 4).

Assim, a aula de escultura e desenho passou a ser ministrada pelo tenente-coronel Fernando Luís Ferreira às quintas-feiras (das 6 às 8 horas da manhã), às terças-feiras e aos sábados (das 17 às 19 horas), beneficiando a todos os educandos “[...] que se acharem aptos para as apprender, e a cada um em particular relativamente ao officio a que se dedicar" (REGULAMENTO, 1848, Art. 67). A cada semestre, o professor deveria informar ao diretor da Casa o adiantamento dos alunos, através de documento escrito, que devia ser encaminhado pelo diretor ao presidente da Província.

Um dos entraves encontrados pelo professor dizia respeito à carência de material didático para que as aulas ocorressem de maneira a fazer com "que os alunos que a freqüentam pudessem aproveitar" (RELATÓRIO, 1855), como estojos, molduras e livros. Esse mesmo material também foi reivindicado pelo professor José de Albuquerque Cardoso Homem, que assumiu interinamente a disciplina por seis meses. Nesse período, foi possível aos educandos artífices aplicar os conhecimentos adquiridos nas molduras e esculturas do Teatro São Luiz, por ocasião de sua reforma, quando da sua incorporação à Província. ${ }^{7} \mathrm{O}$ mesmo ocorreu durante a transformação do Largo do Vale em jardim público.

Em 1855, a Lei no 395, de 18 de julho, estabeleceu “[...] na Casa dos Educandos Artífices desta Província uma cadeira de mecânica, desenho e escultura aplicada às artes, ficando convertidas a que atualmente existe" (Art. $1^{\circ}$ ). Essa cadeira incorporou as noções e as práticas de aritmética, álgebra e geometria com conteúdos preliminares à mecânica, e as "lições de desenho constaram da prática de desenho linear, de aritmética e noções teóricas de perspectivas" (Art. $3^{\circ}$ ). Uma das referências obrigatórias dessa nova aula era o livro Architectura de Paládio, assim como as estampas existentes na Biblioteca Pública, que foram emprestadas à CEA “[...] por um tempo, até que fossem adquiridas pela Casa as mais convenientes" (RELATÓRIO, 1857).

Os conteúdos da disciplina deviam ser ministrados durante dois anos, tempo de duração do curso, "[...] cujo ensino, como he sabido, foi espalhado por toda a Europa, e mesmo he já praticado no Brazil" (FALLA, 1848, p. 30). Para a matrícula no primeiro ano, o aluno deveria saber ler e escrever corretamente e dominar as operações básicas de matemática. Esse primeiro ano tratava-se de um preparatório para as lições de mecânica e contemplava os seguintes conteúdos: aritmética (até a regra de três); álgebra (até a resolução 
de equações de $2^{\circ}$ grau); geometria plana, com aplicação à agrimensura; teoria do desenho e perspectiva linear; e o conhecimento das cinco ordens da arquitetura; todavia, para Antonio Pereira Maya (diretor da CEA), o conteúdo desta aula não contribuía para o "progresso e desenvolvimento dos ofícios mecânicos" (RELATÓRIO, 1859), devendo ser extinta por ser um "objeto de luxo" no estabelecimento, o que resultaria no seu fechamento em 1859.

Em 1862, embora a disciplina em questão tenha voltado a integrar o ensino artístico por determinação da Lei $\mathrm{n}^{\circ}$ 609, de 21 de setembro de 1861, assinada pelo presidente de Província Francisco Primo de Sousa Aguiar, a sua recriação não teve a aprovação do então diretor da CEA, Antonio Pereira Maya, que julgava que ela não ia ao encontro das necessidades e dos interesses do que se praticava no estabelecimento, “[...] que eram as artes industriais, cujo interesse atual estaria restrito a 4 ou 5 alunos" (RELATÓRIO, 1862). No entanto, oito anos mais tarde, essa aula foi frequentada por 74 educandos e 4 alunos externos, com " $[\ldots]$ aprendizagem [...] regular mesmo com todos os esforços do professor Domingos Tribuzzi" (RELATÓRIO, 1870), funcionando sob a sua regência até 1889, quando do encerramento das atividades da CEA.

\section{Aula de Geometria e Aritmética Aplicada às Artes e de Noções Gerais de Aritmética e} Álgebra

A aula de Geometria e Aritmética Aplicada às Artes e de Noções Gerais de Aritmética e Álgebra foi à terceira criada na Casa, ministrada gratuitamente por Raimundo Teixeira Mendes, segundo o método do Mr. Dupin. ${ }^{8}$ Esse professor se destacou na história do Maranhão pelas obras que realizou a serviço do governo, como "[...] o Canal de Arapagaí, fontes do Apicum e do Dique, da Companhia Anil, quando se procedia aos encanamentos à caixa d'água e da Companhia Fluvial de Navegação a Vapor, construindo a casa da fundição" (MARQUES, 1970, p. 249). Esses trabalhos, alegava-se, comprometiam suas atividades docentes, como se queixou Antonio Pereira Maya a Eduardo Olimpio Machado, presidente da Província.

A disciplina foi criada por Portaria do Governo em 25 de junho de 1853 e veio ao encontro dos interesses da Casa: por um lado, ajudou a inserir Teixeira Mendes no campo educacional maranhense; por outro, estando ligada ao Liceu, ganhava status e reconhecimento intelectual. Desde 1848 havia interesse em criá-la, no entanto não havia sido imediatamente possível, por falta de professor habilitado e de recursos da Província para buscá-lo no estrangeiro. Já em referência aos educandos matriculados, estes deveriam apresentar ao professor, por meio do diretor, atestado de que sabiam ler e escrever corretamente e também de que dominavam as quatro operações matemáticas, ministrando-se a disciplina na residência 
do professor, em horários diurnos ou noturnos, conforme a distância entre Instituição e o centro da capital, assim como as inúmeras atividades do docente da cadeira.

Em 30 de junho de 1866, a Lei $n^{\circ} 770$ dividiu essa disciplina em duas: Geometria Prática e Mecânica Aplicada. A primeira funcionava na CEA, enquanto a segunda era ministrada na Casa de Fundição, sendo ambas franqueadas a todos os que quisessem frequentá-las. Os educandos artífices podiam se inscrever na segunda se fossem aprovados na primeira e, ao concluírem ambas, recebiam um certificado de habilitação. Como estímulo à aprendizagem, o Art. $10^{\circ}$ dessa lei determinava que "Os educandos que houverem completado embora não [tivessem] terminado o prazo de retenção a que são obrigados pelo Art. $1^{\circ}$ da Lei $\mathrm{N}^{\mathrm{o}}$ 541, de 30 de julho de 1859, [ficariam], ipso facto, dispensados do tempo [4 anos] que para isso lhes [faltasse]".

Com respeito aos conteúdos, se na cadeira de Geometria Prática eram ensinados elementos de cálculo, geometria, trigonometria, geometria descritiva e a sua aplicação ao desenho linear, ao nivelamento, à agrimensura, ao levantamento de planos, à perspectiva arquitetônica e à teoria e prática da régua do cálculo, na cadeira de mecânica eram lecionados os elementos de mecânica física e suas aplicações às máquinas simples, tais como “[...] alavancas, sarilhos, roldanas, parafusos \& teoria e pratica dos braços das rodas dentadas, bombas, principais rodas hydráulicas; estudo especial practico e theoria das machinas de vapor e desenho de machinas" (REGULAMENTO, 1853).

$\mathrm{Na}$ CEA, essa disciplina era ministrada durante o dia, três vezes por semana; na Casa de Fundição, os horários se alternavam por períodos: duas vezes por semana à noite e uma durante o dia, destinando-se os domingos ao desenho de máquinas. A duração das aulas em ambas as instituições era a mesma: uma hora e meia, podendo ser ministrada pelo mesmo professor, com gratificações diferentes. Já em 1869, a disciplina de mecânica foi transferida para a Casa de Fundição, que oferecia melhores condições físicas e materiais para seu desenvolvimento, além da supervisão constante por parte de Temístocles da Silva Maciel Aranha (substituto do professor João Antonio Coqueiro) sobre as atividades dos educandos, que aprendiam nas oficinas de serralheiro, ferreiro, moldador e carpinteiro. Esse fato geraria uma incompatibilidade de horários entre as aulas, pois as oficinas começavam às 6 horas da manhã, no mesmo período em que os artífices estavam na aula de primeiras letras, mas alterar a programação seria perturbar a regularidade do ensino e os bons resultados que a Casa vinha obtendo em todos os seus anos de criação.

Nesse sentido, Jansen Pereira (substituto de Antonio Pereira Maya), como diretor da CEA, acreditava que o horário dos trabalhos nas oficinas da Casa de Fundição - das 6 horas da manhã às 4 da tarde - poderia ser alterado, ao contrário das aulas oferecidas na CEA, que 
dependiam da disponibilidade do professor. Em face desse impasse, a Lei $\mathrm{n}^{\circ}$ 890, de 6 de julho de 1871, determinou a fusão das duas cadeiras, que passaram a se denominar de Mecânica e Geometria Aplicadas às Artes, sendo ministrada na Casa por Temístocles da Silva Maciel Aranha até ser extinta pela Lei $\mathrm{n}^{\circ} 1.270$, de 11 de maio de 1883, em razão da aposentadoria do professor.

\section{Ciências naturais, agricultura e outras disciplinas}

Por ordem do presidente da Província, foi criada na Casa, em 1863, a aula de Ciências Naturais, a ser ministrada pelo Doutor Caetano Candido Cantanhede, lente dessa mesma cadeira no Liceu, com a finalidade de instrumentalizar os alunos com conhecimentos de física e de química. Essa aula era ministrada três vezes por semana: às segundas, quartas e sextasfeiras, nas dependências do estabelecimento. Entretanto, para funcionar, necessitava de aparelhos e espaço físico para acomodar grafômetros, bússolas, pranchetas, esquadrias de agrimensura, marcos de nível d'água e de nível de bolha de ar, escalas de cobre de duas dimensões, entre outros instrumentos.

Uma questão levantada por Jansen Pereira era que essa disciplina ocupava três dias da semana, alterando os trabalhos da CEA, não obstante somente oito alunos pudessem frequentá-la, haja vista que a maioria fosse de tenra idade ou estivesse empregada nos serviços internos à Instituição. E “[...] outros finalmente são tão broncos e atrasados em tudo, que parece bem inútil frequentarem tal aula, pois que de certo perderão ali o tempo, que pode ser aproveitado em algum outro trabalho" (RELATÓRIO, 1863). Mas, ainda assim, o diretor reconhecia a grande importância dessa disciplina e seu grande proveito para os jovens educandos, se eles não "[...] fossem baldos dos preparatórios para o curso, julgo que o resultado será nenhum" (RELATÓRIO, 1863).

Essa disciplina seria extinta, juntamente com a aula de agricultura, pela Lei ${ }^{\circ} 890$, de 6 de julho de 1870, sob a justificativa do presidente da Província, José da Silva Maya, de que

Esta aula [ciências naturais] é, segundo penso, inteiramente inútil ao
estabelecimento, como o tem provado a experiência. Além de imprópria e estranha
ao fim d'aquella instituição, ella exige nos respectivos alumnos o conhecimento
prévio que lhes falta de certas matérias, como indispensável preparatório para
poderem com proveito receber aquelle ensino. (RELATÓRIO, 1870).

Silva Maya sugere, então, a substituição dessa disciplina por Língua Francesa e Geografia; matérias cujo professor "era reconhecidamente distinto". Justificava o ensino do francês pela importância do idioma, “[...] em cujo dialeto existe tudo quanto de melhor se conhece nas artes" (RELATÓRIO, 1870). Desse modo, acreditava Jansen Pereira "[...] que 
seria mais bem aproveitado o sacrifício da Província, si, em vez da aula de que trato [ciências naturais], fosse estabelecida aqui a cadeira de língua francesa, e este magistério estou certo que o Dr. Carvalho nada deixaria a desejar" (RELATÓRIO, 1870). Nesse sentido, a influência da literatura francesa no território brasileiro e no espaço escolar já estava manifesta e aumentaria gradativamente durante todo o Império, mas deve ser entendida pelas tramas de interesses econômicos e culturais estabelecidas entre ambos os países, e não como decorrência da "importação de modelos" pelas classes dirigentes (BITTENCOURT, 2008). ${ }^{9}$

Com relação à aula de Geografia, dispõe-se de poucas informações sobre ela, certamente pela pouca importância que assumiu na Casa. Esta aula foi criada para atender à vontade do Visconde de Saint Armand, que julgava importante para os jovens aprenderem os fundamentos da Geografia. Porém, desde o seu início, dois problemas se estabeleceram: o primeiro era a falta de tempo do professor, em razão dos trabalhos de engenheiro que executava nas obras públicas da Província; o segundo era a falta de recursos, tais como globos e mapas. Com a sua morte, em 1857, na cidade de Caxias, as aulas foram assumidas pelo professor de primeiras letras Roberto Augusto Colin.

Toda essa dinâmica referente às aulas criadas na CEA, com exceção das de primeiras letras e as relacionadas à música - as de instrumentos de corda e as de instrumentos bélicos -, foi objeto de críticas de todos os diretores e de alguns presidentes de Província. Tais críticas resultavam do fato de julgarem que as disciplinas não iam ao encontro do verdadeiro fim da instituição, qual seja: “[...] dar aos meninos uma educação civil e religiosa, primeiras letras e um oficio mecânico, com a finalidade de que no futuro possam ter um meio honesto de subsistência". Mudanças de disciplinas que vinham materializando um currículo norteador da formação primária e profissional dos alunos na CEA por meio da constante renovação dos conteúdos, exigindo o desaparecimento, a substituição e/ou a simbiose de disciplinas em sintonia com os programas de ensino estipulados e com os regulamentos da instrução pública, fosse em razão do confronto entre presidentes e diretores da instituição ou entre estes últimos e os professores; tensões permeadas por conflitos latentes entre os representantes da política educacional e a margem de manobra das suas ações, segundo as figurações específicas estabelecidas na cadeia de interdependências em que estiveram inseridos (ELIAS, 2001a, 2001b). Por outro lado, este movimento parece estar atrelado às constantes mudanças trazidas pelos avanços teórico-metodológicos implícitos na história das disciplinas, à necessidade de elas estarem vinculadas às próprias concepções e posicionamentos sobre as áreas do conhecimento e sobre a instrução, em consonância com os ofícios e as próprias demandas profissionais, uma vez que estas práticas parecem indicar, “[...] ordinariamente, de fato, que 
os conteúdos de ensino são impostos como tais à escola pela sociedade que a rodeia e pela cultura na qual se banha” (CHERVEL, 1990, p. 181).

\section{Conclusão}

Enfim, acreditamos que, embora as múltiplas interpretações dos representantes institucionais e políticos sobre o papel que deveria exercer a Casa dos Educandos e Artífices no cenário local maranhense para o ensino das primeiras letras e a aprendizagem de um ofício por parte de crianças desvalidas e órfãs tivessem metas bem definidas, que se sustentavam na interpretação e no uso dos dispositivos legais que a definiam como instituição específica, mesmo assim, implícitas à dinâmica que se foi estabelecendo na distribuição das disciplinas enquanto escolha ou substituição, nas mudanças de oficinas, assim como no planejamento delas dentro e fora da instituição, na contratação de professores com disponibilidade e dedicação ao magistério, nos critérios de acesso ao número crescente de educandos e no tipo de aluno, ${ }^{10}$ na organização e na distribuição do tempo escolar, nos modos de organizar e distribuir o espaço, nas práticas dos professores e administradores, bem como nos mecanismos de controle exigidos via regulamento pelos diretores e presidentes da Província, para além do controle planejado, observavam-se as demarcações intelectuais e políticas de seus defensores, que formaram entre si figurações específicas, em virtude das suas interdependências. Figurações que têm "[...] uma relativa independência em relação a indivíduos singulares, mas não aos indivíduos em geral” (ELIAS, 2001a, p. 51), como é possível observar na faixa de idade para entrada e saída do estabelecimento, fixada por decisão de diretores e presidentes: no início, parecia atender ao legislado nos documentos oficiais, mas, a partir de 1850, por exemplo, com o desenvolvimento das aulas de música na banda, a quantidade de educandos participantes e os programas a cumprir, pelos próprios interesses da escola, os sujeitos que participavam extrapolavam o período exigido, permanecendo desde a infância até a maioridade, o que fez com que, paradoxalmente, essas práticas se tornassem uma das mais rentáveis fontes de captação de recursos para a Casa e um meio de angariar reconhecimento e prestígio social, muito embora tenham sido também uma das causas que levaram ao fechamento da $\mathrm{CAE}$, já que iam de encontro à função instituída em lei.

Embora as prescrições sobre os comportamentos infantis e as formas de projeção de mentes e corpos, assim como as possíveis interações entre os educandos, estivessem contempladas nos regulamentos da instituição, a própria existência desta legislação e sua aplicação denunciam os 'efeitos do controle' sobre os infantes, que, se pareciam garantir a generalidade das condutas das crianças e dos jovens alunos em formação, estimulando o 
autocontrole das pulsões e tensões, por outro lado, serviram como vestígios que denunciam que os dispositivos disciplinadores não atendiam a todos na mesma temporalidade, nem com a mesma eficácia. Isto reitera que os problemas relativos “[...] à consciência e impulsos instintivos da criança [e dos adolescentes] variam com a natureza das relações entre elas e os adultos. Essas relações têm em todas as sociedades uma forma específica correspondente às peculiaridades de sua estrutura"; portanto, os problemas decorrentes de adaptação e modelação das crianças e dos adolescentes, os problemas específicos da puberdade, só poderão ser compreendidos “[...] em relação à fase histórica, à estrutura da sociedade como um todo, que exige e mantém esse padrão de comportamento de adulto e esta forma especial de relacionamento entre adultos e crianças[/adolescentes]" (ELIAS, 1994, p. 182).

Destarte, se a escola, de forma geral, com suas regras, prescrições e normas, tem servido para o amoldamento infantil, por meio da pacificação das pulsões e do autopoliciamento dos comportamentos, a Escola dos Educandos e Artífices no Maranhão oitocentista, como 'território de confinamento' desses desvalidos da sorte, visando ao ajustamento social, também parece, na sua generalidade, ter influenciado a maioria das crianças e adolescentes alunos em formação, garantindo, com essa prática educativa, a inserção gradual dos formandos na sociedade e no mercado de trabalho, como meio de lhes garantir o próprio sustento. Em outras palavras, esta instituição, via instrução, parece ter provocado nos educandos, segundo a documentação analisada, uma economia psíquica, que era afetada pela constituição de um novo habitus, baseado na transferência dos mecanismos de controle externos para os internos; portanto, a escola foi fundamental para a "pacificação dos costumes e controle dos afetos" (ELIAS, 1990, p. 80).

\footnotetext{
Notas

${ }^{1}$ A Balaiada foi a mais importante insurreição popular no interior do Maranhão (1839 -1841), com desdobramentos no Piauí e no Ceará. Sublevação constituída por vários grupos com interesses não definidos, provocada pela crise da exportação do algodão, pela imposição da Lei dos Prefeitos e apoiada pela população mais pobre e pelos escravos (MARQUES, 2008). A implantação da Lei dos Prefeitos (como causa primeira baixada pelo governo provincial em 1838) objetivara criar chefes do Executivo fortes nos municípios e fora apoiada pela Lei do Ato Adicional de 1834, que determinava, entre outras medidas, a descentralização do gabinete regencial, criando uma "monarquia federativa". Nesse sentido, os juízes de direito e de paz seriam substituídos por prefeitos e subprefeitos com poderes mais amplos, fortalecendo assim a legitimidade dos Presidentes de Província (CALDEIRA, 1991).

${ }^{2}$ Viveiros, em 1937, em trabalho divulgado em diversas edições do jornal $O$ combate, descobriu no livro de anotações do Liceu, escriturado em 1838, que "[...] de 14 escolas que tínhamos, passamos a 24: duas na capital e uma em Alcântara, Arari, Brejo, Caxias, Guimarães, Icatú, Mearin, Monção, Paço do Lumiar, Pastos-Bons, Pinheiro, Itapecuru, Rosário, S. Bento, S. João de Côrtes, S. Antonio das Almas, S. Vicente Férrer, S. Miguel, Tutóia, Vinhais, Viana e Vargem Grande” (VIVEIROS, 1953, p. 7).

${ }^{3}$ Sobre o método lancastrino, Maria Helena Câmara Bastos e Luciano Mendes de Faria Filho (1999) reuniram, na obra A escola elementar no século XIX: o método monitorial/mútuo, estudos de diversas procedências França, Portugal, Argentina, Brasil -, que procuraram ilustrar um período das ideias e práticas pedagógicas do século XIX: a implantação do ensino monitorial/mútuo.
} 


\footnotetext{
${ }^{4}$ Para entender o surgimento de novas profissões e as correlatas mudanças observadas na vinda da Corte até a Independência, leia História geral da civilização brasileira, tomo II: O Brasil monárquico, v. 1: O processo de emancipação: "A classe média da colônia [...] principia agora a enriquecer-se de elementos porventura mais ativos, ou passa a acolher ofícios antes desconhecidos, numa espécie de cosmopolitismo de que, mesmo em épocas mais tardias, não se conhecerão muitos exemplos" (BARRETO, 2004, p. 11).

${ }^{5}$ Segunda fase da vida, aquela em que "[...] acaba propriamente a infância, pois as palavras infans e puer não são sinônimas" (ROUSSEAU, 1999, p. 65); contudo, no "Emílio há infância na puerilidade, [residindo] nisso [...] uma das mais originais descobertas do tratado pedagógico rousseauniano" (BOTO, 2002, p. 49).

${ }^{6}$ Cf.: Castellanos (2017): O livro escolar no Maranhão Império (1822-1889). São Luís: EDUFMA; Café \& Lápis.

${ }^{7}$ Designado como Teatro União de 1817 até 1852, e depois de Teatro São Luís. Já no Governo de Urbano Santos, recebe a atual denominação de Teatro Artur Azevedo.

${ }^{8}$ Método simultâneo utilizado especificamente para o ensino do cálculo matemático, por meio do qual, o professor poderia ministrar a mesma lição a todos os alunos.

${ }^{9}$ Cf.: CASTELlanOS, Samuel L. V. O livro escolar no Maranhão Império (1822-1889). São Luís: EdUFMA; Café \& Lápis, 2017.

${ }^{10}$ Internos e externos. Cf.: CASTRO, Cesar Augusto. Infância e trabalho no Maranhão provincial. São Luis: EdFUNC, 2007.
}

\section{Referências}

BASTOS, Maria Helena Camara; FARIA FILHO, Luciano Mendes de (org.). A escola elementar no século XIX: o método monitorial/mutuo. Passo Fundo: UPF, 1999.

BITTENCOURT, Circe Maria Fernandes. Livro didático e saber escolar: 1810-1910. Belo Horizonte: Autêntica, 2008.

BOTO, Carlota. O desencantamento da criança: entre a renascença e o século das luzes. In: FREITAS, Marcos Cezar de; KULHMANN JUNIOR, Moysés (org.). Os intelectuais na História da Educação. São Paulo: Cortez, 2002.

CABRAL, Maria do Socorro Coelho. Política e educação no Maranhão: 1834-1889. São Luís: SIOGE, 1989.

CALDEIRA, José de Ribamar C. O Maranhão na Literatura dos viajantes do século XIX. São Luís: AML/SIOGE, 1991.

CARVALHO, Jose Murilo de. A construção da ordem: a elite política imperial. Teatro das sombras: a política imperial. 2. ed. Rio de Janeiro: Civilização Brasileira, 2006.

CASTELLANOS, Samuel L. V. O livro escolar no Maranhão Império (1822-1889). São Luís: EdUFMA; Café \& Lápis, 2017.

CHERVEL, André. História das disciplinas escolares: reflexões sobre um campo de pesquisa. Teoria e Educação, Porto Alegre, v. 2, p. 177-229, 1990.

CUNHA, Luis Antonio. As raízes de ofícios manufatureiros em arsenais, asilos e liceus. Fórum Educacional, Rio de Janeiro, v. 3, n. 3, p. 3-37, jul./dez. 1979.

DIAS, Antônio Gonçalves. Instrução Pública em diversas Províncias do Norte. Rio de Janeiro, 29 de julho de 1952. In: ALMEIDA, José Ricardo de Almeida. História da Instrução pública no Brasil (1500-1889): história e legislação. São Paulo: Educ, 1995. 
DIAS, Antônio Gonçalves. Instrução Pública em diversas Províncias do Norte: relatório de Antonio Gonçalves Dias. Rio de Janeiro: Arquivo Nacional, 1957. v. 39.

ELIAS, Norbert. O processo civilizador. Rio de Janeiro: Jorge Zahar, 1990. v. 1.

ELIAS, Norbert. A sociedade dos indivíduos. Lisboa: Dom Quixote, 1993.

ELIAS, Norbert. A sociedade dos indivíduos. Rio de Janeiro: Jorge Zahar, 1994.

ELIAS, Norbert. Sociedade de corte: investigação sobre a realeza e da aristocracia de corte. Rio de Janeiro: Jorge Zahar, 2001a.

ELIAS, Norbert. Estudos sobre a gênese da profissão naval: cavalheiros e tarpaulins. Mana, Rio de Janeiro, v. 7, n. 1, p. 89-116, abr. 2001b. DOI: http://dx.doi.org/10.1590/S010493132001000100005 .

FALLA que recitou o presidente da Província do Maranhão, Antonio Joaquim Alvares do Amaral, na abertura da Assemblea da mesma Província em 28 de julho de 1848, Maranhão: Typ.de J.A.G de Magalhães, 1848.

FARIAS FILHO, Luciano Mendes de. A infância e sua educação: materiais práticas e representações - Brasil e Portugal. Belo Horizonte: Autêntica, 2004.

FAUSTO, Boris. História do Brasil. São Paulo: EdUSP, 2003.

FONSECA, Celso Suckow da. História do Ensino Industrial no Brasil. Rio de Janeiro: Senai, 1986.

FOUCAULT, Michael. Vigiar e punir. Petrópolis: Vozes, 1975.

FOUCAULT, Michael. Microfísica do Poder. 7. ed. Rio de Janeiro: Forense, 1987.

FRANCO, Luiz A. Carvalho. O ensino de ofícios manufatureiros dirigidos os menores abandonados: Brasil - 1870-1930. 1988. Dissertação (Mestrado em Educação) - Pontifícia Universidade Católica de São Paulo, São Paulo, 1988.

FREITAS, Zoraide Rocha de. História do ensino industrial no Brasil. São Paulo: Departamento de Ensino Profissional do Estado, 1954.

GONDRA, José Gonçalves. Artes de civilizar: medicina, higiene e educação escolar na Corte Imperial. Rio de Janeiro: UERJ, 2004a.

GONDRA, José Gonçalves. Filhos da Sombra: os enjeitados como problema de hygiene no Brasil. In: FARIAS FILHO, Luciano Mendes de. A infância e sua educação: materiais práticas e representações - Brasil e Portugal. Belo Horizonte: Autêntica, 2004b. p. 125-142.

HILSDORF, Maria Luisa Spedo. História da educação brasileira: leituras. São Paulo: Pioneira, 2005.

INSTRUCÇÃO pública da Província do Maranhão. Maranhão, 1855. Mimeo.

KULHMANN JUNIOR, Moysés (org.). Os intelectuais na História da Educação. São Paulo: Cortez, 2002. 
MALERBA, Jurandir. O Brasil Imperial: panorama do Brasil no século XIX. Maringá: EdUEM, 1999.

MARANHÃO. Lei no 105, de 23 de agosto de 1841. Mimeo.

MARANHÃO. Lei no 243 , de 16 de outubro de 1848. Mimeo.

MARANHÃO. Lei no 395, de 18 de julho de 1855. Mimeo.

MARANHÃO. Lei no 541, de 30 de julho de 1859. Mimeo.

MARANHÃO. Lei n ${ }^{\circ}$ 609, de 21 de setembro de 1861. Mimeo.

MARANHÃO. Lei no 770, de 30 de junho de 1866. Mimeo.

MARANHÃO. Lei no 890, de 6 de julho de 1870. Mimeo.

MARANHÃO. Lei nº 1096, de 18 de junho de 1874. Mimeo.

MARANHÃO. Lei nº 1270, de 11 de maio de 1882. Mimeo.

MARANHÃO. Lei no 1270 , de 11 de maio de 1883. Mimeo.

MARQUES, César Augusto. Dicionário histórico-geográfico da Província do Maranhão. Rio de Janeiro: Fon-Fon e Seleta, 1970.

MANACORDA, Mario. História da Educação: da antiguidade aos nossos dias. São Paulo: Cortez, 1989.

PORTARIA de 21 de julho de 1853.

PRACTICA para o serviço da eschola. [S. l.], 20 de setembro de 1845. Mimeo.

REGULAMENTO da Casa de Educandos Artífices. [S. l.], 2 de dezembro de 1841. Mimeo.

REGULAMENTO da Casa de Educandos Artífices. [S. l.], 22 de setembro de 1848. Mimeo.

REGULAMENTO da aula de geometria e mecânica. [S. l.], 25 de junho de 1853. Mimeo.

REGULAMENTO da Casa de Educandos Artífices. [S. l.], 7 de março de 1855. Mimeo.

RELATÓRIO do presidente da Província do Maranhão, o doutor Eduardo Olimpio Machado, na abertura da Assemblea Legislativa Provincial no dia 3 de maio de 1855, accompanhado do orçamento da receita e despesa para o anno de 1856, e mais documentos. [S. l.]: Typ. Const. de I.J. Ferreira, 1855. Mimeo.

RELATÓRIO que á Assemblea Legislativa Provincial do Maranhão apresentou na sessão ordinaria de 1857 o presidente da Província, Dr. Benvenuto Augusto de Magalhães Taques. [S. l.]: Typ. da Temperança, 1857. Mimeo. 
RELATÓRIO do Presidente da Província do Maranhão, o doutor João Lustosa da Cunha Paranaguá, na abertura da Assemblea Legislativa Provincial no dia 3 de maio de 1859. [S. l.]: Typ. de J.M.C. de Frias, 1859. Mimeo.

RELATÓRIO que á Assemblea Legislativa Provincial do Maranhão apresentou o presidente da Província, conselheiro Antonio Manoel de Campos Mello, por occasião da installação da mesma Assemblea no dia 27 de outubro de 1862. S. Luiz do Maranhão: Typ. de B. de Mattos, 1862.

RELATÓRIO que á Assemblea Legislativa Provincial do Maranhão apresentou o conselheiro presidente da Província, Antonio Manoel de Campos Mello, por occasião da installação da mesma no dia 3 de maio de 1863. [S. l.]: Typ. do Frias, 1863.

RELATÓRIO que sua excellencia o senr. vice-presidente da Província, dr. José da Silva Maya, apresentou no dia 18 de maio de 1870 perante a Assemblea Legislativa Provincial, por occasião da installação de sua sessão ordinária. S. Luiz do Maranhão: Typ. de J.M.A. Serrão, 1870.

RIZZINI, Irma. O cidadão polido e o selvagem: a educação dos meninos desvalidos na Amazônia Imperial. 2004. Tese (Doutorado em História Social) - Universidade Federal do Rio de Janeiro, Rio de Janeiro, 2004.

WARDE, Mirian Jorge. Repensando os estudos sociais de história da infância no Brasil. Perspectiva, Florianópolis, v. 25, n. 1, 21-39, jan./jun. 2007.

VIVEIROS, Jerônimo de. Apontamentos para a história da instituição pública e particular do Maranhão. Revista de Geografia e História, São Luís, v. 4, p. 3-43, dez. 1953.

. 125-68, jan./jul. 2003. 